\title{
Effects of Emotional Stability on Computer Game Play
}

\author{
Xiaowen Fang \\ DePaul University \\ USA \\ xfang@depaul.edu
}

\begin{abstract}
With the rise of social media and mobile computing, hedonic components and gamification play a more and more important role in the success of e-business systems. In addition, as a majority of users of e-business have game play experiences, understanding their behavior is essential. This research attempts to investigate user behavior in computer game play and the findings will likely shed lights on how to design gamification features in e-business systems. Based on a conceptual framework of computer game play proposed by Fang, Chan, and Nair [5], an online survey was designed and conducted to investigate the relationship between personality trait and players' choice of games. In addition, we also attempted to examine the hardcore game players who are alleged to be the main driving force behind the gaming industry [4]. Results suggest that the personality trait, emotional stability, has an impact on how players choose games. Findings and their implications were discussed.
\end{abstract}

Keywords: Personality, Emotional Stability, Game Play, Gamification, E-business

DOI: $10.6025 / \mathrm{jitr} / 2018 / 9 / 3 / 77-84$

Received: 20 March 2018, Revised 28 April 2018, Accepted 5 May 2018

(C) 2018 DLINE. All Rights Reserved

\section{Introduction}

The popularity of digital (computer and video) games has reached phenomenal proportions. Based on the statistics provided by Entertainment Software Association [1], $65 \%$ of American households play computer or video games, and their worldwide markets are expected to grow strongly also in the future. Computer games have become a major form of entertainment. In addition, digital games are used increasingly for therapeutic, educational, and work- related purposes ([2], [3]). Given the prominence of computer games for entertainment, researchers need to acquire a better understanding about computer game players and their play experience. However, as Bateman and Boon [4] stated in the preface of their book, "a certain mystery still surrounds game design, and although much has been written on the subject, the formal study of game design practices in a definite sense is still in its infancy." 
Based on a conceptual framework of computer game play proposed by Fang, Chan, and Nair [5], this study investigates the relationship between the personality trait, emotional stability, and players' choice of games. Our key research questions are: 1) what types of people play which kinds of games? 2) What role does the personality trait, emotional stability, play in players' choice of games? We expect that findings of these important questions will no doubt help game designers improve interaction designs in computer games. In addition, the findings will likely shed lights on how to design gamification features in e-business systems.

\section{Background Literature}

Much of the psychological research on games has focused on negative effects of violent video games. Recent studies have started to investigate individual differences among game players. In this section, we first review prior research on personality and computer game play. Then we examine the Big-Five personality model and its personality traits.

\subsection{Personality and Computer Game Play}

Previous research has consistently shown that exposure to violent video games is significantly linked to increases in aggressive behavior, aggressive cognition, aggressive affect, and cardiovascular arousal, and to decreases in helping behavior [6]. Anderson and Dill [6] also suggest that the positive relationship between violent video game play and aggressive behavior and delinquency is stronger for individuals who are characteristically aggressive and for men. Furthermore, a few other studies show that personality is linked to gaming behaviors. Fetchenhauer and Huang [7] indicate that the justice sensitivity could be used to predict decisions in a number of games using theoretical paradigms (dictator games, ultimatum games, and a combination of these two games). Douse and McManus [8] suggest that players of a fantasy Play-By-Mail game were less feminine, less androgynous, and more introverted than matched controls. The fantasy game players showed lower scores on the scale of empathic concern, and were more likely to describe themselves as "scientific," and to include "playing with computers" and "reading" among their leisure interests than players in the control group. In a more recent study, Whang and Chang [9] explored the lifestyles of online game players. Based on an online survey, they classify lifestyles of game players into three groups: single-oriented players, community-oriented players, and off-real world players. Players in each group display distinct differences in their values and game activities, as well as in their anti-social behavior tendencies. This study further suggests that differences in game players' lifestyles reflect not only their personality but also their socio-economic status within the virtual world constructed through game activities.

Bateman and Boon [4] applied to Myers-Briggs Type Indicator [10] to games and conducted a survey to investigate game player types. The survey had two components: a 32- question Myers-Briggs personality test and a short questionnaire to determine elements such as game purchasing and playing habits. About four hundred participants took part in the study. Based on cluster analysis results, Bateman and Boon [4] identified the following four play styles:

- Type 1 Conqueror play involves winning and beating the game.

- Type 2 Manager play revolves around a strategic or tactical challenges.

- Type 3 Wanderer play in which players search for a fun experience.

- Type 4 Participant play.

Within each of these four types, players were further categorized into two subtypes: hardcore and casual players.

Bartle [11] recognizes four types of game players who play games in the virtual world: 1) Achievers like acting on the virtual world. Their aim is usually to succeed in the context of the virtual world. 2) Explorers like interacting with the virtual world. They act in order to find out things about the virtual world and how it works. 3) Socialisers like interacting with other players. They like talking, being part of a group, and helping others. 4) Killers like acting on other players. Sometimes, this is to gain a big bad reputation, but other times it's to gain a big good reputation.

More recently, Fang and Zhao [12] find: 1) Sensation seeking has a significant and positive effect on enjoyment of computer game play through enhanced engagement during game play for action/ adventure/shooting/fighting, role playing, and sport/ racing games. 2) Sensation seeking has a significant and positive effect on enjoyment of computer game play through enhanced cognition values for family entertainment/simulation games. 3) Self-forgetfulness has a significant and positive effect on

$78 \quad$ Journal of Information Technology Review Volume 9 Number 3 August 2018 
enjoyment of computer game play through enhanced engagement during game play for role playing games.

Despite some of the groundbreaking work in prior studies, few research has systematically examined what role player's personality might play in choosing games to play. This paper reports one of the first attempts to address this research question.

\subsection{The Big-Five Personality Model}

Personality can be defined as a stable set of tendencies and characteristics that determine the commonalities and differences in people's psychological behavior (thoughts, feelings and actions) that have continuity in time. Personality is one of the most elusive areas of psychology, difficult to understand, and difficult to test. Nevertheless, psychologists have developed several theories to explain personality based on two principles: core of personality and periphery of personality. Core of personality addresses the inherent attributes of human beings which do not change over the course of living. They are used to explain the similarities among people. Periphery of personality, on the other hand, focuses on learned attributes. It helps to identify the differences among people.

Over the years, the big five-factor personality model ([13], [14], [15], [16]) has gained acceptance among researchers because it establishes a common taxonomy ([17]). It contains the following five dimensions (or traits) of personality:

- Extraversion: This factor has been the largest. It contrasts traits such as talkativeness, liveliness, and outgoingness versus shyness, quietness, and passivity.

- Agreeableness: The second factor. It contrasts traits such as kindness and gentleness with rudeness and harshness.

- Conscientiousness: The third factor. It includes traits such as organization, discipline, and thoroughness versus sloppiness, laziness, and unreliability.

- Emotional Stability (Versus Neuroticism): The fourth factor. This factor contains traits such as relaxedness, versus moodiness, anxiety, and touchiness.

- Intellect or Imagination: The fifth factor. It has traits such as philosophicalness, complexity, and creativity versus shallowness and conventionality. This factor also has another name, openness to experience.

The Big Five model has been researched and validated by many different psychologists and is at the core of many personality questionnaires. According to McCrae \& Costa [14], the emotional stability factor can be further refined into six facets: anxiety, angry hostility, depression, self-consciousness, impulsiveness, and vulnerability.

In this study, we applied the big-five personality model in gaming and focus on the fourth trait: emotional stability.

\section{Theoretical Framework}

Lazzaro [18] identifies four fun keys in a research conducted at XEODesign: 1) Fiero (emotion of triumph over adversity) from the hard fun of challenge and mastery. Players focusing on the game's challenge, strategic thinking, and problem solving favor this fun key. 2) Curiosity from the easy fun of exploration and role-play. Players enjoy intrigue and curiosity. 3) Relaxation from serious fun. Many players enjoy the visceral, behavior, and cognitive experience that games create. 4) Amusement from people fun. Players also use games as mechanisms for social experiences.

Based on media enjoyment theories, personality theories, and the technology acceptance model, Fang, Chan, and Nair [5] propose a conceptual model of computer game play as depicted in Figure 1.

The prior research on computer game play strongly suggests that emotion is an essential element in the computer game play experience. Therefore, we hypothesize that emotional stability, as the fourth personality factor in the Big- Five personality model that governs how well people manage their emotional responses, will affect players' choice of games.

Hypothesis 1: Computer game players will choose games whose interactions are compatible with their emotional stability trait.

H1a: Computer game players who have a high score of emotional stability will likely play a game that stimulates dramatic emotional responses. H1b: Computer game players who have a low score of emotional stability will likely play a game that 


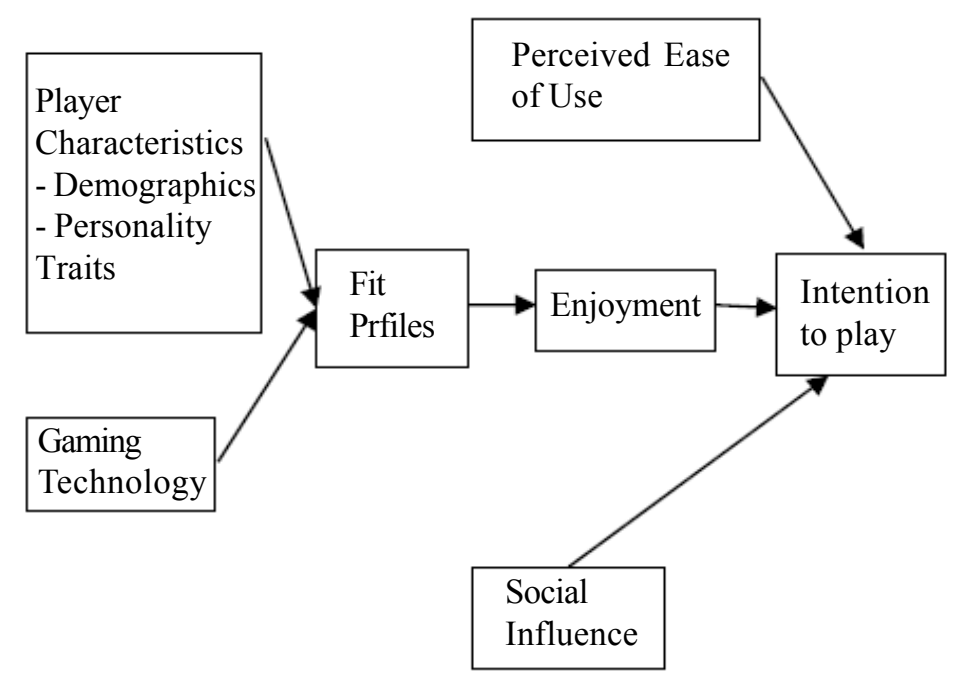

Figure 1. A framework of computer game play [5]

stimulates less changes in emotional responses.

H1b: Computer game players who have a low score of emotional stability will likely play a game that stimulates less changes in emotional responses.

Based on a series of field studies, Csikszentmihalyi [19] creates the flow theory, an understanding of the process by which certain behaviors make life more enjoyable. One element of flow state is the balance between challenge and skill. When user skills are properly matched with the challenges presented in a task, a flow experience will be possible. In computer game play, if we consider a player's emotional stability as the skill to manage his/her emotion, a match between the challenge (stimuli for emotional responses) presented in a game and his/her skill (emotional stability) will likely lead to flow experience and consequently enjoyment. Therefore, game players will likely choose games that stimulate emotional responses compatible to their emotional stability.

\section{Method}

An online survey was conducted to test the hypothesis. The survey questionnaire contains three types of questions: questions about player's demographics and gaming experience, questions about personality traits, and questions about enjoyment of playing a particular computer game.

Game enjoyment was measured by an 11-item instrument proposed by Fang et al. [20].

Personality traits were measured using the 50 item IPIP [21] inventory available at http://ipip.ori.org/. Since its inception in 1999, IPIP has been used in over 60 studies and translated in over 20 languages.

In the beginning of the survey, a participant was first asked to answer questions about his/her demographics and gaming experience such as how often and how long he/she has played computer games. Then the participant would answer 50 questions about his/her personality. Upon finishing the personality questions, the participant was instructed to choose one or more games that he/she regularly plays and assess his/her play experience by answering questions about game enjoyment. If the participant chose more than one game, only one game could be assessed at a time. All the personality and enjoyment questions were randomized for each participant to avoid order effect. Participants were not allowed to skip any questions.

\section{Results}

\subsection{Participants and Descriptive Statistics}

The survey was conducted in four universities in three different countries: US, Korea, and China. In total, 1096 computer game 
players responded to the survey. Table 1 presents the descriptive statistics of participants' demographic information.

\subsection{Validation of Survey Instrument}

A factor analysis was conducted to establish the discriminant and construct validity. Only items highly loaded (loadings $>0.5$ ) on one of the following constructs were retained in the analysis: extraversion, agreeableness, conscientiousness, emotional stability, intellect, affect, behavior, and cognition. The first five constructs are the big five personality factors and the last three are the factors of game enjoyment.

Reliability analysis was performed. Cronbach's Alpha values were calculated to check the internal consistency of the items. Table 2 shows Cronbach's alpha values of all eight constructs. All of these alpha values were above 0.7 and satisfactory.

\begin{tabular}{|c|c|c|}
\hline \multicolumn{3}{|l|}{ Variables } \\
\hline Gender & $\begin{array}{l}\text { Male (\%) } \\
\text { Female (\%) }\end{array}$ & $\begin{array}{l}85.2 \\
14.8\end{array}$ \\
\hline Culture & $\begin{array}{l}\text { American (\%) } \\
\text { Korean (\%) } \\
\text { Chinese (\%) }\end{array}$ & $\begin{array}{l}85.6 \\
10.3 \\
4.1\end{array}$ \\
\hline Age & $\begin{array}{l}\text { Mean } \\
\text { Std. }\end{array}$ & $\begin{array}{l}25.7 \\
6.99\end{array}$ \\
\hline $\begin{array}{l}\text { How long have you been } \\
\text { playing computer/video } \\
\text { games? }\end{array}$ & $\begin{array}{l}\text { Mean (years) } \\
\text { Std. }\end{array}$ & $\begin{array}{l}14.8 \\
8.94\end{array}$ \\
\hline $\begin{array}{l}\text { How many hours on } \\
\text { average do you play? }\end{array}$ & $\begin{array}{l}\text { Mean } \\
\text { Std. }\end{array}$ & $\begin{array}{l}2.81 \\
2.126\end{array}$ \\
\hline $\begin{array}{l}\text { How often do you play } \\
\text { computer/video games? }\end{array}$ & $\begin{array}{l}\text { Daily (\%) } \\
\text { Weekly (\%) } \\
\text { Monthly (\%) } \\
\text { Seldom (\%) }\end{array}$ & $\begin{array}{l}41.3 \\
40.7 \\
9.0 \\
9.0\end{array}$ \\
\hline
\end{tabular}

Table 1. Demographic Information of Participants

\begin{tabular}{|l|l|}
\hline Construct & Cronbach's Alpha \\
\hline Extraversion & 0.893 \\
\hline Agreeableness & 0.788 \\
\hline Conscientiousness & 0.779 \\
\hline Emotional Stability & 0.876 \\
\hline Intellect & 0.786 \\
\hline Affect & 0.731 \\
\hline Behavior & 0.823 \\
\hline Cognition & 0.730 \\
\hline
\end{tabular}

Table 2. Cronbach's Alpha Values

Therefore, the survey instrument was valid and reliable. 


\begin{tabular}{|c|c|c|c|}
\hline \multirow[t]{2}{*}{ Genre } & \multirow[t]{2}{*}{$\mathbf{N}$} & \multicolumn{2}{|c|}{ Subset } \\
\hline & & 1 & 2 \\
\hline Sims & 23 & 2.934783 & \\
\hline FIFA & 40 & 3.165000 & 3.165000 \\
\hline StarCraft & 62 & 3.214516 & 3.214516 \\
\hline WorldofWarcraft & 97 & 3.215464 & 3.215464 \\
\hline Civilization & 14 & 3.235714 & 3.235714 \\
\hline CommandandConquer & 25 & 3.236000 & 3.236000 \\
\hline LegendofZeldaTwilight & 20 & 3.250000 & 3.250000 \\
\hline LegoStarWars & 14 & 3.250000 & 3.250000 \\
\hline NeedforSpeed & 33 & 3.266667 & 3.266667 \\
\hline Crysis & 11 & 3.272727 & 3.272727 \\
\hline GuitarHero & 24 & 3.275000 & 3.275000 \\
\hline Quake & 14 & 3.357143 & 3.357143 \\
\hline Doom & 23 & 3.369565 & 3.369565 \\
\hline SuperMario & 34 & 3.397059 & 3.397059 \\
\hline SidMeiersCivilization & 15 & 3.400000 & 3.400000 \\
\hline Halo & 66 & 3.410606 & 3.410606 \\
\hline CallofDuty & 115 & 3.415652 & 3.415652 \\
\hline GrandTheftAuto & 54 & 3.422222 & 3.422222 \\
\hline WarcraftIII & 44 & 3.429545 & 3.429545 \\
\hline SimCity & 13 & 3.430769 & 3.430769 \\
\hline ResidentEvil & 22 & 3.431818 & 3.431818 \\
\hline Diablo & 44 & 3.443182 & 3.443182 \\
\hline SuperSmashBros & 29 & 3.468966 & 3.468966 \\
\hline MarioKart & 15 & 3.473333 & 3.473333 \\
\hline ElderScrollsIVOblivion & 29 & & 3.486207 \\
\hline FinalFantasy & 28 & & 3.517857 \\
\hline Battlefield & 28 & & 3.521429 \\
\hline Bioshock & 23 & & 3.526087 \\
\hline AssasinsCreed & 40 & & 3.585000 \\
\hline MaddenNFL & 38 & & 3.610526 \\
\hline DevilMayCry & 22 & & 3.613636 \\
\hline Fallout & 20 & & 3.625000 \\
\hline CounterStrike & 30 & & 3.630000 \\
\hline Rainbow & 13 & & 3.661538 \\
\hline HalfLife & 41 & & $\begin{array}{r}3.71463 \\
4\end{array}$ \\
\hline
\end{tabular}

Note: The score was out of 5 (maximal score) and $p$ value $<0.05$.

Table 3. Pair-wise Comparisons of Emotional Stability Scores Among Different Game Titles 


\subsection{Pair-Wise Comparison Analysis}

In order to detect personality differences among players of different games, pair-wise comparisons of emotional stability scores among different game titles were performed. The following procedure was used in this analysis: 1) All responses were grouped by game titles. Different editions of the same game title were assigned the same title with the assumption that these different editions should have the similar characteristics and can be categorized as the same kind of game. For example, "Call of Duty", "Call of Duty 2", and "Call of Duty 3" were assigned the same title "CallofDuty". 2) Game titles that were assessed by at least 10 different game players were selected for this analysis. 3) Pair-wise comparisons of emotional stability scores were performed among all game titles with at least 10 responses. Table 3 presents the pair-wise comparison results.

Table 3 clearly shows that players of different game titles have different emotional stability scores. It indicates that the personality trait, emotional stability, may actually affect players' choice of games. To understand the true differences among different game titles, the game falling only in cluster 1 ("Sims") and the ones falling only in cluster 2 ("ElderScrollsIVOblivion", "FinalFantasy", "Battlefield", "Bioshock", "AssasinsCreed", "MaddenNFL", "DevilMayCry", "Fallout", "CounterStrike", "Rainbow", and "HalfLife") were compared.

In the cluster 1, "Sims" is a strategic life-simulation computer game developed by Maxis and published by Electronic Arts. The Sims focuses entirely on the lives of "Sims", placing the player in control of their virtual "world" and their daily activities, such as sleeping, eating, reading, and bathing. Its game interactions will less likely trigger dramatic emotional responses. As shown in Table 3, players of this game title had lower emotional stability scores than those of other game titles. Therefore, hypothesis H1b is supported.

All the game titles falling only in cluster 2 ("ElderScrollsIVOblivion", "FinalFantasy", "Battlefield", "Bioshock", "AssasinsCreed", "MaddenNFL", "DevilMayCry", "Fallout", "CounterStrike", "Rainbow", and "HalfLife") involve shooting, adventuring, sporting, and other exciting experience. These excitements will no doubt trigger dramatic changes in emotional responses. Players of all these game titles had higher emotional stability scores than those of other games. Therefore, hypothesis H1a is also supported by observations from our online survey.

A correlation analysis reveals that no significant correlations were found between the emotional stability scores and scores of enjoyment-related constructs: affect, behavior, and cognition. The correlation analysis suggests that the differences presented in Table 3 were not related or confound to enjoyment of game players.

\section{Conclusions}

The online survey we conducted presents compelling evidence that the personality trait, emotional stability, impacts on game players' choice of game. The implications of this finding to interaction designers of computer games are profound. By changing the design of interactions in a game, a game designer can turn it to serve a completely different audience. It is also interesting to find that contrary to what game industry believes, the hardcore game players don't have different personalities from ordinary players.

However, the findings from this study are far from conclusive due to some limitations: 1) the participants might not be representative although we tried very hard to draw players from different geographic regions and different institutions. 2) The measurement of personality might not be sufficiently accurate since we only measured the high-level big-five personality factors but not the finer personality facets within each big-five factor. 3) The sample size was still relatively small in terms of number of assessed game titles and number of responses for each game title. 4) There had been little control exercised in the data collection to exclude confounding factors.

As future steps, we will continue to: 1) refine the personality instrument to measure finer personality traits, 2) collect more data to build a larger and more representative sample, and 3) create a more controlled experiment environment to investigate the possible causal relationship between player's personality and choice of games.

\section{References}

[1] Entertainment Software Association, "The essential facts about the computer and video game industry," Retrieved December 2009, from http://www.theesa.com/facts/index.asp, 2017. 
[2] Griffiths, M. D. (2003). The therapeutic use of videogames in childhood and adolescence, Clinical Child Psychology and Psychiatry, 8, 547- 554.

[3] Robillard, G., Bouchard, S., Fournier, T., Renaud, P. (2003). “Anxiety and presence during VR immersion: A comparative study of the reactions of phobic and non-phobic participants in therapeutic virtual environments derived from computer games," CyberPsychology \& Behavior, 6. 467-476.

[4] Bateman, C., Boon, R. (2006). 21st Century game design," Charles River Media, Inc.: Hingham, MA.

[5] Fang, X., Chan, S., Nair, C. (2009). An Online Survey System on Computer Game Enjoyment and Personality, Proceedings of HCI International.

[6] Anderson, C. A., Dill, K. E. (2000). Video games and aggressive thoughts, feelings, and behavior in the laboratory and in life, Journal of Personality and Social Psychology, 78 (4) 772-790.

[7] Fetchenhauer, D., Huang, X. (2004). Justice sensitivity and distributive decisions in experimental games, Personality and Individual Differences, 36, 1015-1029.

[8] Douse, N. A., McManus, I. C. (1993). The personality of fantasy game players, British Journal of Psychology, 84, 505-509.

[9] Whang, L. S., Chang, C. (2004). Lifestyles of virtual world residents: living in the online game "lineage. Cyberpsychology \& Behavior, 7 (5) 592-600.

[10] Briggs, S. R., The optimal level of measurement for personality constructs, In: D. M. Buss, \& N. Cantor (Eds.), Personality psychology: Recent trends and emerging directions (p. 246-260). 1989. New York: Springer-Verlag.

[11] Bartle, R. A. (2009). Understanding the limits of theory. In Bateman (Ed.), Beyond game design: nine steps toward creating better videogames, Course Technology: Boston, MA. 2009.

[12] Fang, X., Zhao, F. (2009). Sensation Seeking, Self Forgetfulness, and Computer Game Enjoyment, In: Proceedings of HCI International.

[13] Digman, J., Takemoto-Chock, N. (1981). Factors In The Natural Language Of Personality: Re-Analysis, Comparison, And Interpretation Of Six Major Studies, Multivariate Behavioral Research, 16 (2) 149.

[14] McCrae, R., Costa, P. (1985). Comparison of EPI and Psychoticism scales with measures of the five factor model of personality, Personality and Individual Differences 6, p. 587-597.

[15] Peabody, D., Goldberg, L. (1989). Some determinants of factor structures from personality-trait descriptors, Journal of Personality and Social Psychology, 57 (3) 552-567.

[16] Tupes, E. C., Christal, R. E. (1961). Recurrent personality factors based on trait ratings, USAF ASD Tech. Rep. No. 61-97, Lackland Airforce Base, TX: U. S. Air Force. 1961.

[17] Goldberg, L. R. (1990). An alternative 'description of personality: The Big- Five factor structure, Journal of Personality and Social Psychology, 59(6), 1990, 1216-1229.

[18] Lazzaro, N. (2009). Understanding emotions, In: Bateman (Ed.), Beyond game design: nine steps toward creating better videogames. Course Technology: Boston, MA. 2009.

[19] Csikszentmihalyi, M. (1993). The evolving self: A psychology for the third millennium. New York: Harper Collins. 1993.

[20] Fang, X., Chan, S., Brzezinski, J., Nair, C. (2008). Measuring Enjoyment of Computer Game Play, In: Proceedings of the Fourteenth Americas Conference on Information Systems (AMCIS 2008). 